\title{
A presença do acompanhante na urgência.
}

\section{The presence of the accompanying person in emergency.}

\section{La presencia del acompañante em urgencia.}

Ana Carolina Guarnieri

Danielle Abdel Massih Pio

RESUMO: O paciente em situação de urgência enfrenta, além da dor física, o impacto emocional do adoecimento. Nesse contexto, o paciente pode estar com um acompanhante que nem sempre é bem acolhido pela instituição hospitalar. Este estudo teve por objetivo compreender o significado dado pelo paciente à presença do acompanhante na urgência e avaliar relações e práticas envolvidas nesse cenário. Trata-se de uma pesquisa exploratória qualitativa realizada com doze pacientes de uma unidade de pronto-socorro em um hospital-escola. Para o tratamento das entrevistas, foram utilizados o método da análise de conteúdo temática e referenciais teóricos de saúde pública, da Política Nacional de Humanização e da Psicologia Hospitalar. Os temas que emergiram possibilitaram discussão das dificuldades encontradas pelos usuários. Destaca-se o papel do acompanhante como fonte de suporte emocional, colocado pelo paciente como auxiliar na comunicação com a equipe. É enfatizada a importância do acolhimento ao paciente e ao acompanhante, porém, conclui-se que ainda são muitos os desafios nos serviços de emergência, pela necessidade de adequação de sua estrutura para a assistência ocorrer de forma integral, resolutiva e humanizada.

Palavras-chave: Acesso aos serviços de saúde; Humanização da assistência; Acolhimento; Assistência hospitalar.

\begin{abstract}
The patient in emergency situations faces, beyond physical pain, the emotional impact of the illness. In this context the patient can be accompanied by a relative who is not always welcomed by the hospital institution. The objective of this study was to understand the meaning given by the patient to the presence of the accompanying person in emergency and evaluate relations and practices involved in this scenario. This is a qualitative exploratory study carried out with twelve patients from an emergency room in a teaching hospital. For the treatment of the interviews, the method of the thematic content analysis and theoretical references of public health, National Humanization Policy and Hospital Psychology were used. The themes which emerged enabled the discussion about the problems faced by the users. Noteworthy is the role of the accompanying
\end{abstract}


person as a source of emotional support, placed by the patient as an auxiliary in communication with the team. It is emphasized the importance of embracing the patient and accompany, however, it is concluded that there are still many challenges for the emergency services, by the need to adapt its structure for the assistance to occur in an integral, resolutive and humanized way.

Keywords: Health services accessibility; Humanization of assistance; User embracement; Hospital care.

RESUMEN: El paciente en situación de urgencia enfrenta, aparte del dolor físico, el impacto emocional de la enfermedad. En este contexto el paciente puede tener un acompañante, no siempre acogido por el hospital. El objetivo de este estudio fue comprender el significado dado por el paciente a la presencia del acompañante en la emergencia y evaluar las relaciones y las prácticas involucradas en este escenario. Se trata de una investigación exploratoria cualitativa realizada en doce pacientes de una unidad de urgencia en un hospital de la escuela. Para el tratamiento de entrevistas se utilizó el método de análisis del contenido temático y referencias teóricas de salud pública, Política Nacional de Humanización y Psicología de la Salud. Los temas que surgieron permitieron la discusión de las dificultades encontradas por los usuários. Se puede destacar el papel del acompañante como fuente de apoyo emocional, colocada por el paciente como un auxiliar en comunicarse con el equipo. Es enfatizada la importancia de dar la bienvenida al paciente y acompañante, pero concluye aún hay muchos desafios para los servicios de urgencia por la necesidad en adaptar su estructura con condiciones para la asistencia ocurrir de manera integral, resoluta y humanizada.

Palabras clave: Accesibilidad a los servicios de salud ; Humanización de la atención; Acogimiento; Atención hospitalaria.

\section{INTRODUÇÃO}

Parte-se atualmente de uma concepção mais abrangente do cuidado em saúde e da articulação dos serviços com relação à sua localização, aos fluxos e níveis de atenção. Com o objetivo de ampliar o acesso e aprimorar a qualidade da atenção à saúde no Sistema Único de Saúde (SUS), o Ministério da Saúde (MS) iniciou a implantação de Redes Temáticas prioritárias, com recursos estratégicos para organização dos serviços. Entre elas, destaca-se a Rede de Atenção às Urgências e Emergências (RUE), implementada através da Portaria $n^{\circ} 1.600$, de $2011 .{ }^{1}$

ARUE é composta por diferentes serviços, como Unidades de Saúde da Família (USF), Unidades Básicas de Saúde (UBS), Serviço de Atendimento Móvel às Urgências (SAMU), Serviço de Resgate do Corpo de Bombeiros, Unidades de Pronto Atendimento (UPAs 24h) e Prontos-Socorros. Nos atendimentos realizados, são definidas as diretrizes, que seguem os princípios do SUS, priorizando a universalidade, a equidade e a integralidade da atenção à saúde a partir do acolhimento dos pacientes e da busca da humanização. ${ }^{1,2}$ 
A definição médica das situações de urgência e emergência está relacionada ao tipo de atendimento e de risco. A urgência é definida como um episódio imprevisto que envolve um agravo à saúde com ou sem risco potencial de vida, em que o sujeito necessita de atendimento médico imediato. Por sua vez, a emergência é definida como uma condição de agravo à saúde que envolve o risco iminente de vida ou de sofrimento intenso. Ambas as situações podem ser de ordem clínica, referentes a traumas, eventos envolvendo desastres, atos de violência, entre outros. ${ }^{3}$

Em pesquisa realizada em um serviço de pronto-socorro, Rossi et al. ${ }^{4}$ revelam, através das falas dos entrevistados, a distância entre a definição médica de urgência e a urgência psíquica. Entretanto, por mais que o especialista avalie a queixa como não urgente, o paciente possui uma percepção diferente, de outra ordem, e solicita atenção ao seu problema de saúde. Os autores chamam a atenção para o fato de que muitos pacientes conseguem relacionar o surgimento de sintomas com fatos de sua vida ou situações estressantes que desencadearam a procura pelo atendimento, e que no crivo biomédico acabam sendo frequentemente ignoradas.

Destacando fatores de impacto relacionados ao ambiente da unidade de atendimento às urgências e emergências, Perez ${ }^{5}$ elenca a necessidade de agilidade, a imprevisibilidade das ações e dos acontecimentos, a sobrecarga de trabalho dos profissionais da equipe e uma taxa de mortalidade significativamente maior que de outros setores do hospital. Somam-se a esses os problemas estruturais dos hospitais públicos e a descaracterização do que é demanda de pronto-socorro, pois muitos pacientes em busca de assistência para seu problema recorrem diretamente a essa porta de entrada, gerando baixa resolutividade e sobrecarga para o serviço. A partir dessa situação, tornase, muitas vezes, impraticável a comunicação dialógica entre o profissional de saúde e o usuário, em que é necessária a escuta das reais necessidades expressas pelo sujeito que recebe o cuidado, avaliando-se as razões do sofrimento, indo além da lógica biomecanicista.

Partindo de uma visão mais abrangente do conceito de saúde, sabe-se que as experiências de vida estressantes e os fatores subjetivos contribuem para o desenvolvimento de um adoecimento biológico. Da mesma forma, o adoecimento traz consigo repercussões psíquicas, como, por exemplo: o temor frente a um possível desequilíbrio emocional; a adaptação a um meio novo e, algumas vezes, hostil; e ameaças à autoimagem e à integridade física, muitas vezes, inerentes aos tratamentos e ao processo de adoecer. Tal situação traz consigo o sentimento de perda de controle do ambiente e de si mesmo, com um alto grau de imprevisibilidade, onde a capacidade de adaptação dos sujeitos é colocada à prova. ${ }^{6,7}$

No contexto da urgência, o paciente enfrenta dores psíquicas ligadas ao seu corpo biológico, relacionadas ao impacto dos traumas na vida, adoecimento agudo ou até mesmo a piora de um estado crônico. Entram em cena fantasias, medos, inseguranças, ansiedades e sentimentos variados, entre eles, a impotência e a solidão. ${ }^{7}$ Muitas vezes, nesse cenário, o paciente está acompanhado por um familiar, amigo, vizinho ou conhecido. Esses vínculos apresentam particularidades entre a díade paciente-acompanhante, potencializadas ao ver alguém querido sujeito à dor e dependente

ISSN 1982-8829 Tempus, actas de saúde colet, Brasília, 11(4), 41-57, dez, 2017. Epub Ago/2018 
de tratamentos invasivos. Tal situação pode suscitar ansiedades, inseguranças e sentimentos ambivalentes frente ao atendimento e à equipe.

Nesse sentido, Beuter et al. ${ }^{8}$ destacam que o interesse em participar do cuidado recebido pelo paciente e o apoio recebido da equipe para empreender essa tarefa são fatores importantes para o bem-estar dos doentes e acompanhantes. No entanto, as instituições hospitalares nem sempre estão preparadas para receber esse acompanhante, por possuírem expectativas diferentes sobre o papel de cada um no contexto hospitalar. Squassante e Alvin ${ }^{9}$ pontuam em seu trabalho que, para a equipe do hospital estabelecer uma relação de qualidade com o acompanhante, muitas vezes, aquela espera que este seja alguém que "não reclame", "não atrapalhe" e "ajude nos cuidados com o paciente", sendo que tal cuidado é permeado por indefinições frente ao que é papel de cada um. Por sua vez, o acompanhante espera que a equipe "trate bem" e "seja atenciosa", tanto do ponto de vista técnico quanto da relação com o paciente e o familiar.

Portanto, com relação à presença do acompanhante, vários questionamentos podem ser feitos, como: que tipo de apoio ou estressor ele pode trazer para a situação com o paciente e a equipe; e, também, como pode ser definida sua participação durante o processo de cuidado. Em uma situação de urgência, o acompanhante pode evidenciar que tipo de recursos possui para estar junto do paciente. Esses recursos, além de se basearem em possibilidades sociais e emocionais para o cuidado, podem ser potencializados a partir das condições que a instituição oferece para receber o acompanhante. Nesse sentido, o espaço físico e as informações sobre o estado de saúde do doente são aspectos importantes. ${ }^{5}$

Considerados esses fatores envolvidos no atendimento institucional, com as dificuldades para organização, manejo e preparo para lidar com as situações, a Política Nacional de Humanização (PNH), implantada no Brasil em 2003, propõe mudanças nos modos de gerir o sistema e cuidar dos usuários. A partir dessa política, novas possibilidades foram pensadas para o cuidado em saúde a partir da valorização dos sujeitos, sejam eles os pacientes, gestores ou trabalhadores. Uma delas é a proposta da clínica ampliada, que se refere a uma mudança no pensamento sobre o indivíduo doente, percebendo-o como alguém que, além de sua doença, possui outras dimensões em sua existência, como as sociais, emocionais e espirituais. Assim, pensar no cuidado em saúde demanda mais do que um diagnóstico e uma terapêutica específica, mas o cuidado ampliado ao paciente e o ambiente que o rodeia, inclusive sua família e comunidade. ${ }^{10,11}$

Ceccim e Merhy ${ }^{12}$, em reflexão crítica sobre políticas de atenção em saúde, inclusive a PNH, destacam a importância dos encontros vivenciados no trabalho vivo, para que a pressão do ambiente não torne homogêneo o que é singular nas relações e nas práticas. Um exemplo é a questão levantada no presente estudo sobre a presença do acompanhante, em que se faz necessário analisar como as indicações da política podem ser consolidadas no cenário hospitalar de urgência.

Percebe-se, então, o valor prático de investigações sob a ótica dos diversos participantes 
desse processo, a começar pelo próprio paciente, com seu olhar sobre a presença e o significado do acompanhante na situação de urgência vivenciada. Sendo assim, o objetivo deste estudo foi compreender o significado dado pelo paciente à presença do acompanhante em situação de urgência e avaliar aspectos das relações e práticas envolvidas nesse contexto propício a intervenções, que consideram a saúde mental e o cuidado ampliado.

\section{MATERIAL E MÉTODOS}

O estudo foi realizado no pronto-socorro de um hospital-escola, público, localizado em um município do interior paulista. Sua área de abrangência inclui 62 municípios, com população estimada de 1.200.000 habitantes. O pronto-socorro constitui-se como porta de entrada do SUS para urgências clínicas, ortopédicas, psiquiátricas, entre outras, articulando-se com as redes municipais de atendimento em saúde. Por se tratar de um hospital-escola, é cenário de práticas para estudantes, estagiários e residentes. No ano de 2015, a unidade hospitalar da qual o pronto-socorro faz parte realizou, ao todo, 5.691 internações e 2.834 cirurgias, sendo que a partir deste ano o atendimento em prontos-socorros passou a ser referenciado e teve a implantação da Classificação de Risco. ${ }^{13}$

No citado serviço, os critérios para permissão do acompanhante apresentam-se diferenciados de acordo com o setor em que se encontram os pacientes. Na sala de emergência, não há direito a acompanhante. $\mathrm{O}$ acompanhante é liberado pela equipe enquanto o paciente se encontra em atendimento, sendo medicado ou em observação. Na admissão na unidade de internação, o acompanhante é permitido para idosos acima de 60 anos de idade, menores de idade e pacientes dependentes, isto é, que precisam de auxílio para alimentação, higiene e comunicação.

Os participantes do estudo foram pacientes atendidos na unidade de urgência/emergência adulto, portadores de qualquer patologia na entrada do serviço, no ano de 2014. O critério de inclusão para a seleção dos participantes da pesquisa foi a presença do acompanhante em algum momento do atendimento, e os critérios de exclusão foram: a ausência do acompanhante em todas as fases do atendimento ou limitações cognitivas, físicas e motoras que impossibilitariam a realização das entrevistas. Para a determinação do número de entrevistas, foi utilizado o princípio da saturação teórica, ou seja, quando as informações se tornaram repetitivas, a coleta de dados foi encerrada. ${ }^{14}$

Trata-se de uma pesquisa exploratória qualitativa, que tem como pressupostos o direcionamento gradual de seus objetivos a partir da interação do pesquisador com seu objeto de estudo, considerando aspectos diversos dos fenômenos estudados. A pesquisa qualitativa tem se mostrado um importante instrumento no estudo das questões relacionadas à saúde por diversos fatores, como a busca de flexibilidade e a investigação do contexto onde ocorre o fenômeno. ${ }^{15}$ Esse tipo de pesquisa vai ao encontro dos objetivos desta investigação, por considerar a dinamicidade do tema e as percepções dos entrevistados, com suas vivências na área da saúde.

Um roteiro de entrevista semiestruturado foi utilizado, de modo a orientar a abordagem do tema- 
chave da pesquisa e a contemplar os objetivos específicos. Composto por questões relativas aos dados socioeconômicos dos pacientes e por seus motivos da procura pelo atendimento, o roteiro continha perguntas cujas propostas pretendiam possibilitar que o participante descrevesse sua experiência em buscar o hospital, detalhando, também, a sua percepção sobre a presença de seu acompanhante durante o atendimento e a relação estabelecida entre o acompanhante e a equipe de saúde.

As entrevistas foram realizadas nos consultórios de atendimento médico, a fim de preservar o sigilo e a privacidade dos participantes da pesquisa. Porém, em alguns casos específicos, devido às limitações físicas dos pacientes, a entrevista foi realizada nos próprios leitos de internação, com as devidas adequações para que o participante estivesse acompanhado apenas da entrevistadora no momento da coleta de dados.

O presente estudo foi avaliado e aprovado em 02/04/14 pelo Comitê de Ética em Pesquisa, emitido sob o $\mathrm{n}^{\mathrm{o}}$ 577.845. As entrevistas ocorreram em agosto de 2014 e foram gravadas em áudio, mediante a autorização dos participantes envolvidos através da assinatura do Termo de Consentimento Livre e Esclarecido (TCLE).

Os depoimentos foram analisados individualmente, extraindo-se as unidades de significado que emergiram da própria transcrição e dos objetivos do estudo. Os dados coletados por meio das entrevistas foram transcritos e analisados de acordo com o método descrito por Bardin ${ }^{16}$, que consiste em definir unidades de significado e categorias temáticas, compostas basicamente dos dados mais relevantes encontrados nas falas dos entrevistados, constituídos por pontos de divergência e convergência relacionados aos assuntos levantados. O referencial teórico utilizado para a discussão deste trabalho se constitui por estudos de saúde pública, da Política Nacional de Humanização e da Psicologia Hospitalar.

\section{RESULTADOS}

Foram entrevistados 12 pacientes, denominados com a letra "P", seguida de numeral, para manutenção de seu sigilo. Quanto à caracterização dos participantes, estes encontravam-se na faixa etária de 22 a 76 anos; eram, em sua maioria, mulheres (sete participantes); e metade era casada. Com relação à escolaridade: uma participante era analfabeta; três iniciaram os estudos, possuindo ensino fundamental incompleto; cinco participantes concluíram o ensino médio; uma possuía ensino médio incompleto; e dois deles concluíram um curso de graduação. Quatro participantes afirmaram ser católicos, quatro evangélicos, uma adventista do sétimo dia, uma testemunha de Jeová, e dois responderam não ter religião. Quanto à ocupação, nove dos participantes responderam que estavam empregados, dois deles aposentados e uma afastada do trabalho, recebendo auxílio-doença. A maior parte dos participantes possuía uma renda mensal entre um e dois salários mínimos, na época da pesquisa, no valor de $\mathrm{R} \$ 724,00$. Seus diagnósticos eram diversificados e se compunham de patologias clínicas e cirúrgicas. 


\section{Características da situação de urgência e do acesso aos serviços de saúde}

Quando questionados sobre o que se lembravam da situação de urgência vivenciada, os pacientes trouxeram respostas que refletem o foco no aspecto biológico presente no ambiente hospitalar, especialmente de atendimento às urgências. Em suas falas, os participantes trouxeram a descrição das dores sentidas, dos medicamentos, exames e procedimentos.

Por volta das 5 da manhã, eu acordei com náusea, muita ânsia de vômito, e a dor já persistente, não parava, dor muito forte! Lado direito do abdômen... em volta do umbigo e se estendia até o abdômen, e aí era uma contração. Eu sentia a dor no lado direito, e a contração descia como uma contração. Vinha a cada um minuto e não parava mais. (P2)

Outro aspecto trazido nas respostas dos pacientes foram os fatores que influenciaram a decisão de ir ao pronto-socorro. Muitas das respostas envolveram a percepção de que o sofrimento era muito intenso e que havia a necessidade de ajuda, ainda que existissem resistências para procurar o hospital.

É! Sinceramente, não queria vir, não (risos). Aí, bom, mas tive que vir por causa dos problemas de saúde mesmo. Estava tanto interferindo na minha saúde, como no meu trabalho e no meu dia a dia, né? (P4)

Vim, vim direto pra cá pro pronto-socorro. Que a hora que eu comecei a sentir dor, eu falei pro meu marido: pelo amor de Deus, me ajuda, que eu não tô aguentando. (P9)

A procura pelo atendimento médico, algumas vezes, iniciava-se em outros serviços da rede, e alguns participantes evidenciaram o fluxo, repleto de obstáculos operacionais, que seguiram para ter acesso ao atendimento. Ao relembrar a situação de urgência vivenciada, os pacientes também trouxeram algumas percepções sobre esses ambientes.

Eu vim pra G. (município da região), e, aí, como eu tava sentindo muita dor, eu fui pro pronto atendimento de lá. Lá, fiquei internada. Passei uma noite lá. Fiquei tentando vaga em uma outra instituição. Aí, de lá, eu vim de ambulância pra Santa Casa, que saiu pelo CROSS (Central de Regulação) uma vaga lá. Só que chegou lá, eles não aceitaram, disseram que não faziam esse tipo de tratamento lá. Aí, o médico da ambulância trouxe a gente pra cá, conversou aqui, e daí aqui eles tariam podendo me receber. (P3)

E os médicos também tudo em cima, e aparelho pra cá, aparelho pra lá. Eu melhorei. Agora eu tô boa! (P6)

Eu tenho um trauma muito grande aqui do Hospital, porque minha irmã ficou no corredor quando teve aneurisma, e também meu cunhado também ficou aqui. Faz uns 6, 7 anos que eles morreu. Então, não gosto muito do hospital, por causa disso. (....) E eu vi minha irmã no corredor, fiquei no corredor também aqui, uns 3, 4 dias na maca. Então, eu, pra mim, essa experiência não gostei nenhum pouco! Mas agora eu tô melhor, que tô lá no fundo, né? Então, por isso que eu não gosto desse hospital. Tenho nada contra 
Pelas falas dos participantes, evidencia-se a multiplicidade das experiências e emoções que podem ser vivenciadas na situação de urgência. Essas vivências podem ser facilitadas ou dificultadas pela maneira com a qual se dá o acesso e o acolhimento no serviço hospitalar.

\section{O papel do acompanhante no processo de adoecimento e hospitalização: vínculo e cuidado}

Em questões que abordavam "Como foi ter a presença do acompanhante durante o atendimento recebido?" e, também, "Qual a sua opinião sobre a importância de ter alguém nesse papel?", os participantes trouxeram dados importantes. Sinalizaram em suas falas a percepção de que a presença do acompanhante influencia diretamente os cuidados prestados pela equipe, bem como a agilidade do atendimento.

Foi bom porque a pessoa tem mais atitude do que a pessoa que tá ruim (risos). Consegue falar pro médico, tomar providência do que tá acontecendo. (P1)

Ah, ia ser bem mais difícil. E eu acho que ia demorar muito mais meu atendimento. Porque ele também, assim, ajudou na agilização do meu atendimento, porque ele ia atrás pra saber o que que ia fazer, o que que ele podia ajudar, o que que ele podia agilizar, né? Pra melhorar minha situação. (P9)

O acompanhante também foi descrito pelos pacientes como uma fonte importante de suporte emocional para o enfrentamento de situações de solidão, desamparo e adoecimento.

Sim, eu me senti mais segura. É uma pessoa que eu sei que não me abandona. Assim, deu uma segurança mesmo, porque já foi tão difícil vir e enfrentar tudo isso. Ela me ajudou. (P7)

Não, depois que ela viu como tava, ela me convenceu a ir no médico. Vixe! Tenho pavor de ir no médico. (P11)

Ah, eu achei legal. A gente precisa... A gente precisa dos outros todo dia. Precisa, porque ninguém vive sem depender de ninguém. Você já viu isso aí? Então, na hora da doença que é mais necessário. (P10)

Alguns dos pacientes evidenciaram em suas falas que, no atendimento em uma situação de urgência, a qualidade do papel do acompanhante está relacionada ao tipo de vínculo estabelecido com o paciente, envolvendo a confiança e a proximidade, principalmente dos familiares.

Não, se fosse um estranho, vinha. Mas um estranho não sabe o que eu tenho, né? Podia ter sido uma mulher do posto... Não sabe o que eu tenho. Sabe que eu tô doente, mas não sabe dos meus problemas (...). Então, eu confio muito nele! (P6)

Minha sobrinha é sempre aquela, aquela... chego não, cadê o tio? Cadê o tio? Pergunta das coisas... (P10) 
Percebe-se, assim, a necessidade e a importância do acompanhante, não só enquanto agente de cuidados e comunicação, mas, também, como alguém vinculado ao paciente, que propicia conforto emocional em uma situação de hospitalização.

\section{Percepções sobre os direitos e deveres com relação à presença do acompanhante: encontros e desencontros}

A respeito da recepção e da relação da equipe de saúde com o acompanhante, alguns pacientes evidenciaram a permissão da presença da pessoa que acompanha nos atendimentos e procedimentos como um fator positivo.

Eu, particularmente, eu não tive o que reclamar. Dessa vez que eu vim, eu não tive o que reclamar, porque ele esteve... Em todos os exames que eu fiz, ele tava junto. Eles não questionaram em nenhum momento, não falaram assim... Não pediram pra se retirar, nada... Sempre foi minha escolha: se eu quisesse que ele estivesse, se eu quisesse que ele se retirasse. Dessa vez, eu não tive do que reclamar. Não tive o que reclamar dessa questão do acompanhante, não. Foi tratado bem também. (P2)

Então, eu até admirei. Que aqui eles recebem muito bem o acompanhante, né? Eu, minha irmã... Se ela quiser entrar, ela entra. Coloca o papelzinho, né? Eu achei, assim, uma benção ter o acompanhante. (P7)

Outra questão apontada como diferencial na recepção dos acompanhantes no pronto-socorro foi o fornecimento de informações por parte da equipe.

Eles trataram bem todo mundo que teve aqui comigo. Deram informação, conversaram. (P5)

Ah, tudo que pergunta, eles responde, tal. Perguntou, perguntou do médico, eles vão lá e chama o médico. Bem tranquilo mesmo. (P8)

Em algumas respostas, os pacientes trouxeram dados sobre algumas dificuldades na relação entre a equipe de saúde e os acompanhantes, ora reforçando algumas competências necessárias no papel de acompanhante, ora destacando dificuldades próprias dos profissionais.

Porque tem uns acompanhante que não têm... Como fala? Aqueles que conversam demais e não tem desconfiômetro. Aqueles que acham que não estão no hospital, que estão em casa. (P7)

É a mesma coisa! Porque esses momento, assim... Tem muitas enfermeiras que são alegres, e tem muitas que são de cara fechada. Que, às vezes, aquela de cara fechada não aprendeu ainda distrair do movimento. Então, se você tá com problema lá, deixa o problema lá e vem pro serviço e mostra aquele seu lado alegre, sorrindo, cantando. (P10)

Percebe-se a complexidade dos aspectos envolvidos na relação entre os profissionais de saúde, pacientes e acompanhantes pelas dificuldades em se atender às demandas objetivas e subjetivas características do cenário de urgências.

ISSN 1982-8829 Tempus, actas de saúde colet, Brasília, 11(4), 41-57, dez, 2017. Epub Ago/2018 


\section{DISCUSSÃO}

Em estudos sobre os serviços de atendimento às urgências, especificamente sobre os profissionais de enfermagem, esse tipo de local é definido como um ambiente em que as ações precisam ser rápidas e eficientes. O tempo é limitado, e os pacientes estão em situações extremas, "entre a vida e a morte". ${ }^{17}$ As diversas intervenções, os métodos diagnósticos e o hábito de se tratar as doenças, e não os indivíduos, podem ocasionar um processo de despersonalização, na qual o paciente perde o contato com sua subjetividade e passa a seguir uma rotina rígida, sem espaço individual. ${ }^{7}$ Em alguns casos, o paciente, então, defende-se, utilizando mecanismos que envolvem questionamentos e resistências. Em outras, no entanto, percebe-se, como ilustrado pela fala de P2, uma postura de reprodução do discurso biomédico.

Giglio-Jacquemot ${ }^{18}$ apresenta a perspectiva antropológica com relação a esse ambiente, para a qual a saúde e a doença possuem definições e percepções independentes das origens predominantemente biomédicas. Completa que a doença não precisa existir do ponto de vista biológico para ser vivida, sendo representada e sentida pelo doente, a partir de sua perspectiva pessoal e também cultural. Diferencia, assim, a "doença do doente", e a "doença do médico", ambos com diferentes conceitos do que é urgente. A partir do discurso dos pacientes, ao descreverem o processo de seu adoecimento, pode-se perceber que sua vivência é traduzida apenas pela descrição sumária de sintomas físicos, representação social possível de uma demanda de pronto-socorro.

A resistência na procura pelo tratamento e, também, na sua adesão durante o período de internação pode expressar sentimentos de insegurança frente ao adoecimento. Barbosa et al. ${ }^{19}$ comentam, acerca da situação de afastamento imposta ao doente ao ser hospitalizado, que, estando ele adaptado à sua rotina e ao seu círculo social, vê-se fragilizado ao ser colocado em um novo ambiente. Chamam a atenção para o fato de que estar em uma unidade de emergência coloca o sujeito em contato com sua vulnerabilidade e finitude. Assim, pode-se pensar que precisar ir ao pronto-socorro envolve aceitar que se está doente e que existem riscos, um processo complexo e doloroso.

Os motivos que levam os pacientes a procurar o hospital são diversificados. A decisão de ir até o serviço e a escolha do mesmo perpassam a gravidade do problema de saúde e a complexidade da necessidade, as tecnologias disponíveis, a resolutividade e o acolhimento do local procurado, as condições do acesso, experiências prévias pessoais ou familiares e o vínculo estabelecido com a instituição. ${ }^{20}$

O pronto-socorro apresenta algumas características que podem justificar essa procura inicial. A partir de uma visão fragmentada do processo de adoecimento, esse serviço se coloca com as portas abertas, facilitando o acesso à saúde, ainda que em caráter emergencial, sem necessariamente atuar em profundidade na problemática vivida pelo usuário. ${ }^{21}$ Em situação de fragilidade, os indivíduos acabam procurando o serviço no qual sua demanda é observada e atendida, pois, em 


\section{$51 / /$}

um pronto-socorro, não se pode negar a entrada dos pacientes, sem que seja dado pelo menos um direcionamento à sua queixa.

O acesso aos serviços de ugência e emergência se dá por várias portas de entrada, desde a atenção básica até os serviços mais complexos, como é o caso do pronto-socorro. No entanto, em todos os serviços pertencentes à rede de atenção, o acolhimento se faz importante. O MS, em documento sobre Acolhimento e Classificação de Risco ${ }^{2}$, aponta desafios específicos do atendimento às urgências, como: a superlotação, o processo de trabalho fragmentado e atravessado por relações rígidas de poder, a exclusão dos usuários e a pouca articulação entre os serviços.

Acolher, nesse sentido, seria, então, considerar as necessidades dos sujeitos, incluindo-os no processo de produção de saúde nas urgências. ${ }^{2,10}$ Realizando uma leitura crítica da fala dos entrevistados, podem-se identificar dados diferentes sobre a experiência de chegar ao prontosocorro: o "passeio" em diversos serviços, o atendimento focado em tecnologias e as experiências de sofrimento já vivenciadas e esperadas.

De acordo com Ismael ${ }^{6}$, é ilusório considerar que o tratamento é sempre considerado pelo paciente como algo desejável e positivo. As falas destacadas evidenciam a singularidade das experiências e percepções a respeito do hospital. Percebe-se que, no primeiro caso, a participante relaciona as intervenções médicas e o uso de tecnologias com sua melhora, relação que pode não ser estabelecida por todos os pacientes, que podem vivenciar essa experiência como uma invasão ou como ações sem sentido. Por sua vez, P7 expõe as lembranças suscitadas pelo ambiente hospitalar, onde sofreu perdas, e, colocada na mesma situação, depara-se com a intensidade de seus sentimentos.

Diante de realidades tão diversas, o acolhimento em todas as etapas do atendimento pode se apresentar como uma ferramenta indispensável à efetivação de práticas mais humanizadas e com maior direcionamento para a integralidade do cuidado, guiado por uma visão abrangente das necessidades dos sujeitos. ${ }^{10}$

Essa questão aparece, também, na pesquisa de Sousa et al. ${ }^{22}$, na qual os participantes apresentam o acompanhante como facilitador, quando fala com o paciente sobre as ações do cuidado e suas implicações; ou dificultador da tarefa de cuidado no ambiente hospitalar, quando é agressivo com a equipe, não colabora com informações necessárias para um tratamento adequado ou age com indiferença com relação ao paciente.

No momento do adoecimento, ter o acompanhante como referência constitui um recurso importante de apoio. Além de toda a fragilidade que a hospitalização impõe ao paciente, essa situação coloca o indivíduo em proximidade com a possibilidade de morrer, seja pela sua própria situação ou pela observação de outros pacientes. Assim, a morte, tão negada em nosso contexto cultural, emerge como uma ameaça à integridade do ser. ${ }^{23,24}$ Nesse sentido, a presença do acompanhante pode proporcionar ao paciente um ponto de equilíbrio, uma fonte de suporte emocional durante a 
experiência de adoecimento, pois possibilita a ligação com um elo social já consolidado, bem como a intermediação com o mundo exterior.

Na perspectiva do familiar, o momento do adoecimento de seu ente querido suscita sentimentos ambíguos: de um lado, a ansiedade e a incerteza causadas pela preocupação frente à situação, e, de outro, a gratificação por estar presente e poder auxiliar a pessoa doente. O paciente, por sua vez, ao se encontrar no hospital, vê-se afastado do seu convívio familiar, convívio este pouco considerado no cuidado recebido. ${ }^{8}$

As falas dos participantes denotam a importância que atribuem à confiança e à segurança advindas do acompanhante, função que pode ser equiparada com a função materna. Winnicott ${ }^{25}$ define a maternagem como a atitude da mãe com relação aos bebês e o cuidado a eles dispensado. A pessoa que exerce a função materna oferece seu ego para alguém em posição frágil, de maior dependência. Serve, assim, como um ego auxiliar, que o ajuda a se integrar psiquicamente em um momento de crise.

Assim, ao se pensar nos acompanhantes no contexto hospitalar, podemos identificar particularidades das relações entre eles e os indivíduos que irão receber esse cuidado, como o tipo de vínculo que possuem e a dinâmica que estabelecem no contexto hospitalar. No entanto, a equipe também exerce papel importante nessa dinâmica, podendo potencializar aspectos positivos da função de acompanhante ou acrescentar fatores ansiogênicos à conturbada situação de urgência.

A autonomia para decidir sobre a presença do acompanhante está relacionada às ações norteadas pela $\mathrm{PNH}$, que visam ao protagonismo dos sujeitos envolvidos no processo de cuidado à saúde. ${ }^{10}$ Por sua vez, a permissão da permanência do acompanhante se apresenta como uma questão controversa, pois, apesar de aparecer como uma diretriz específica para o ambiente hospitalar, a visita aberta depende da dinâmica de cada unidade hospitalar.

Assim, só ficam garantidos por lei, em seus respectivos Estatutos, os acompanhantes de crianças, parturientes e idosos em instituição hospitalar. ${ }^{26-28}$ Entre esse intervalo de idade, com algumas exceções, os serviços estabelecem regras quanto ao direito de ter um acompanhante, ou não as estabelecem, ficando os pacientes e acompanhantes em dúvida se essa presença é desejada pela instituição ou, pelo contrário, incômoda e submetida a definições arbitrárias.

Na Portaria $\mathrm{n}^{\mathrm{o}} 1.820$, de 13 de agosto de 2009, o MS apresenta direitos dos usuários do SUS, entre eles, o direito a: "Art. $3^{\circ}$ II - informações sobre o seu estado de saúde, de maneira clara, objetiva, respeitosa e compreensível". ${ }^{29}$ Além da questão do direito, Vieira ${ }^{7}$ pontua que conhecer sua doença e os aspectos do tratamento pode auxiliar o paciente a lidar com suas ansiedades, diminuindo fantasias e ideias preconcebidas. Ter contato com informações permite que o paciente possa ser mais ativo e tenha mais controle com relação à sua recuperação.

São esperadas algumas competências do acompanhante, definidas na fala do P7, por ter uma 
postura diferente da que se pode ter em casa, isto é, seguir as regras formais e informais da convivência no hospital. Por outro lado, a postura esperada do profissional de saúde, na fala do P10, é que, além que cuidar, a equipe precisa demonstrar satisfação nessa atividade.

De acordo com o Caderno sobre Visita Aberta e Direito ao Acompanhante, do Humaniza SUS $^{30}$, existem alguns elementos que explicam as dificuldades das instituições em receber os acompanhantes, como: a visão de que o acompanhante atrapalha o trabalho no hospital, apresentando-se como mais uma demanda a ser contida; a falta de profissionais e estrutura física para acolher os acompanhantes; a dificuldade de profissionais, gestores, usuários e familiares em compreender a função do acompanhante; e a ausência de condições para permanência em tempo integral do acompanhante.

Ainda sobre as limitações do acompanhante, a ambiência coloca-se como uma questão importante para a permanência em serviços de saúde. Definida como "tratamento dado ao espaço físico, entendido como espaço social, profissional e de relações interpessoais, que deve proporcionar atenção acolhedora, resolutiva e humana"31 , a ambiência engloba elementos sensoriais e a reflexão sobre processos de trabalho e de cuidado, considerando a flexibilidade dos projetos às novas demandas. Assim, nos diversos ambientes e espaços, é necerssário que existam condições para receber o acompanhante e possibilitar encontros produtivos com a equipe de saúde.

Frente à questão do acompanhante no pronto-socorro, usuários e profissionais precisam ser olhados em suas necessidades. Para isso, aparecem como recursos a Clínica Ampliada e o Projeto Terapêutico Singular ${ }^{11}$, que buscam definir coletivamente condutas terapêuticas articuladas para indivíduos ou grupos. Além das questões discutidas neste trabalho, sobre a percepção de pacientes quanto à importância do acompanhante na urgência, para que exista acolhimento, é preciso que a equipe tenha condições de trabalhar com os acompanhantes de acordo com as singularidades das situações, tão imprevistas e diversificadas no pronto-socorro.

\section{CONSIDERAÇÕES FINAIS}

Durante este trabalho, foi possível identificar algumas dificuldades encontradas no acesso dos usuários aos serviços de saúde, nos quais procuram escuta para suas diversas necessidades. Necessidades essas que não se resumem aos sintomas físicos que caracterizam uma urgência no sentido biomédico, mas demandas amplas concernentes ao que é do ser humano e às suas dimensões sociais, culturais, psíquicas e biológicas. Dessa forma, destaca-se a importância da constante reflexão e do aprimoramento da prática do acolhimento por todos os profissionais envolvidos no processo de cuidado.

O acolhimento torna-se ainda mais necessário quando se leva em consideração toda a fragilidade que a hospitalização promove, intensificada em uma situação de urgência, em que a incerteza e a angústia são dominantes para o indivíduo que adoece e se depara com suas limitações. $\mathrm{O}$ 
acompanhante, então, aparece como uma importante fonte de suporte emocional nesse processo de adaptação, servindo como elo com o exterior, auxiliando na comunicação com a equipe de saúde. Porém, ainda que toda a importância da presença do acompanhante tenha sido reconhecida através de políticas públicas, principalmente pela $\mathrm{PNH}$, ainda observa-se uma dificuldade no entendimento de direitos e deveres envolvidos nos atendimentos de saúde. Assim, não só o direito à presença do acompanhante, como o direito à informação e o estímulo à autonomia ficam subordinados à organização dos serviços de saúde e aos seus fluxos de trabalho e cuidado.

No entanto, ainda que essa crítica possa ser realizada, é necessário levar em conta as diversas dificuldades encontradas pelos profissionais em concretizar práticas mais humanizadas nos espaços em que trabalham. Por esse motivo, outros estudos podem ser realizados para melhor entendimento do tema, através da investigação da perspectiva do profissional de saúde, do acompanhante e de outros aspectos colocados pelas políticas públicas.

\section{REFERÊNCIAS}

1. Brasil. Ministério da Saúde. Secretaria de Atenção à Saúde. Departamento de Atenção Especializada. Manual Instrutivo da Rede de Atenção às Urgências e Emergências no Sistema Único de Saúde (SUS). Brasília: Ministério da Saúde; 2013.

2. Brasil. Ministério da Saúde. Secretaria de Atenção à Saúde. Política Nacional de Humanização da Atenção e Gestão do SUS. Acolhimento e classificação de risco nos serviços de urgência. Brasília: Ministério da Saúde; 2009.

3. Conselho Federal de Medicina. Resolução no 1451, de 17 de março de 1995. Diário Oficial [da República Federativa do Brasil]. Brasília, 17 mar. 1995; Seção 1, p. 3666.

4. Rossi L, Gavião ACD, Lucia MCS, Awada SB. Psicologia e emergências médicas: uma aproximação possível. Psicologia hospitalar, 2004;2(2). Disponível em: [http://pepsic.bvsalud. org/scielo.php?pid=S1677-74092004000200009\&script=sci_arttext], acesso em [15 de março de 2014].

5. Perez GH. O psicólogo na unidade de emergência. In: Ismael SMC, organizadora. A prática psicológica e sua interface com as doenças. São Paulo: Casa do Psicólogo; 2010. p. 53-65.

6. Ismael SMC. A inserção do psicólogo no contexto hospitalar. In: Ismael SMC, organizadora. A prática psicológica e sua interface com as doenças. São Paulo: Casa do Psicólogo; 2010. p. 17-35.

7. Vieira MC. Atuação da psicologia hospitalar na medicina de urgência e emergência. Revista da Sociedade Brasileira de Clínica Médica. 2010;8(6):513-9. Disponível em: [http://files.bvs.br/ upload/S/1679-1010/2010/v8n6/a1602.pdf], acesso em [15 de março de 2014]. 
8. Beuter M, Brondani CM, Szareski C, Cordeiro FR, Roso CC. Sentimentos de familiares acompanhantes de adultos face ao processo de hospitalização. Escola Anna Nery Revista de Enfermagem. 2012;16(1):134-40. Disponível em: [http://www.scielo.br/pdf/ean/v16n1/v16n1a18. pdf], acesso em [15 de março de 2014].

9. Squassante ND, Alvim NAT. Relação equipe de enfermagem e acompanhantes de clientes hospitalizados: implicações para o cuidado. Revista Brasileira de Enfermagem. 2009;62(1):11-7. Disponível em: [http://www.scielo.br/pdf/reben/v62n1/02.pdf], acesso em [15 de março de 2014].

10. Brasil. Ministério da Saúde. Secretaria-Executiva. Núcleo Técnico da Política Nacional de Humanização. HumanizaSUS: Política Nacional de Humanização: a humanização como eixo norteador das práticas de atenção e gestão em todas as instâncias do SUS. Brasília: Ministério da Saúde; 2004.

11. Brasil. Ministério da Saúde. Secretaria de Atenção à Saúde. Núcleo Técnico da Política Nacional de Humanização. Clínica ampliada, equipe de referência e projeto terapêutico singular. Brasília: Ministério da Saúde; 2008.

12. Ceccim RB, Merhy EE. Um agir micropolítico e pedagógico intenso: a humanização entre laços e perspectivas. Interface: comunicação, saúde, educação, 2009;13(1):531-42. Disponível em: [http://www.scielo.br/pdf/icse/v13s1/a06v13s1.pdf], acesso em [15 de novembro de 2014].

13. Fundação Municipal de Ensino Superior de Marília. Relatório de Atividades, 2015. Disponível em [http://www.famema.br/institucional/documentos/docs/Rel\%20Famema\%20 Corrigido\%202015.pdf], acesso em [20 de janeiro de 2017].

14. Minayo MCS. O desafio do conhecimento: pesquisa qualitativa em saúde. $13^{\mathrm{a}}$ ed. São Paulo: Hucitec; 2013.

15. Constantino EP., organizador. Percursos da pesquisa qualitativa em Psicologia. São Paulo: Art \& Ciência; 2007.

16. Bardin L. Análise de conteúdo. São Paulo: Edições 70; 2012.

17. Menzani G, Bianchi ERF. Stress dos enfermeiros de pronto socorro dos hospitais brasileiros. Revista Eletrônica de Enfermagem, 2009;11(4):327-33. Disponível em: [http://www. fen.ufg.br/fen_revista/v11/n2/pdf/v11n2a13.pdf], acesso em [15 de novembro de 2014].

18. Giglio-Jacquemot A. Urgências e emergências em saúde: perspectivas de profissionais e usuários. Rio de Janeiro: Fiocruz; 2005. 
19. Barbosa LNF, Pereira JA, Alves V, Ragozini CA, Ismael SMC. Reflexões sobre a ação do psicólogo em unidades de emergência. Revista SBPH, 2007;10(2):73-82. Disponível em: [http:// pepsic.bvsalud.org/pdf/rsbph/v10n2/v10n2a09.pdf], acesso em [15 de março de 2014].

20. Marques GQ, Lima MADS. Demandas de usuários a um serviço de pronto atendimento e seu acolhimento ao sistema de saúde. Revista Latino-Americana de Enfermagem, 2007;15(1):1319. Disponível em: [http://www.scielo.br/pdf/rlae/v15n1/pt_v15n1a03.pdf], acesso em [15 de novembro de 2014].

21. Souza MF, Figueiredo LA, Pinto IC. Análise da utilização do serviço de pronto-socorro na percepção do usuário. Ciência, Cuidado e Saúde, 2010;9(1):13-20. Disponível em: [http:// periodicos.uem.br/ojs/index.php/CiencCuidSaude/article/view/5242/5731], acesso em [15 de novembro de 2014].

22. Sousa L, Almeida A, Simões CJ. Vivências em Serviço de Urgências: o papel dos acompanhantes dos doentes. Saúde e Sociedade, 2011;20(1):195-206. Disponível em: [http:// www.scielo.br/pdf/sausoc/v20n1/21.pdf], acesso em [15 de março de 2014].

23. Kovács MJ. Educação para a morte. Psicologia, Ciência e Profissão, 2005;25(3):484-97. Disponível em: [http://www.scielo.br/pdf/pcp/v25n3/v25n3a12.pdf], acesso em [15 de novembro de 2014].

24. Hohendorff JV, Melo WV. Compreensão da morte e desenvolvimento humano: contribuições à psicologia hospitalar. Estudos e Pesquisas em Psicologia, 2009;9(2):480-92. Disponível em: [http://www.revispsi.uerj.br/v9n2/artigos/pdf/v9n2a14.pdf], acesso em [15 de novembro de 2014].

25. Winnicott DW. Os bebês e suas mães. São Paulo: Martins Fontes; 2006.

26. Brasil. Lei no 8.069 , de 13 de julho de 1990. Dispõe sobre o Estatuto da Criança e do Adolescente e dá outras providências. Diário Oficial [da República Federativa do Brasil]. Brasília, 16 jul. 1990; Seção 1, p. 1.

\section{Brasil. Lei no 11.108 , de 7 de abril de 2005.}

Altera a Lei no 8.080, de 19 de setembro de 1990, para garantir às parturientes o direito à presença de acompanhante durante o trabalho de parto, parto e pós-parto imediato, no âmbito do Sistema Único de Saúde - SUS. Diário Oficial [da República Federativa do Brasil]. Brasília, 7 abr. 2005; Seção 1, p. 1.

28. Brasil. Lei $n^{\circ} 10.741$, de $1^{\circ}$ de outubro de 2003. Dispõe sobre o Estatuto do Idoso e dá outras providências. Diário Oficial [da República Federativa do Brasil]. Brasília, 3 out. 2003; Seção 1, p. 1. 
29. Brasil. Ministério da Saúde. Carta dos direitos dos usuários da saúde. Brasília: Ministério da Saúde; 2011.

30. Brasil. Ministério da Saúde. Secretaria de Atenção à Saúde. Núcleo Técnico da Política Nacional de Humanização. HumanizaSUS: visita aberta e direito a acompanhante. Brasília: Ministério da Saúde; 2010a.

31. Brasil. Ministério da Saúde. Secretaria de Atenção à Saúde. Núcleo Técnico da Política Nacional de Humanização. Ambiência. Brasília: Ministério da Saúde; 2010 b.

Artigo apresentado em 29/01/17

Artigo aprovado em 15/02/18

Artigo publicado no sistema em 30/08/18 